Supplement of Foss. Rec., 24, 357-377, 2021

https://doi.org/10.5194/fr-24-357-2021-supplement

(C) Author(s) 2021. CC BY 4.0 License.

(c) (1)

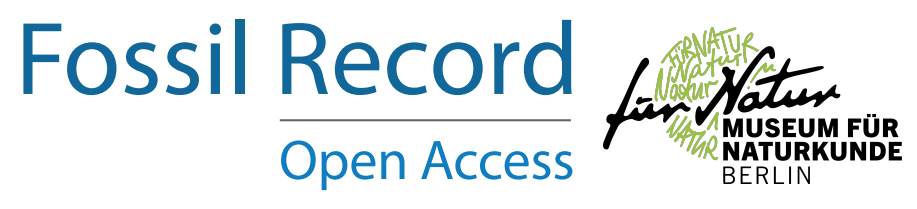

Supplement of

\title{
Ontogenetic development of the European basal aquatic turtle Pleurosternon bullockii (Paracryptodira, Pleurosternidae)
}

\author{
Andrea Guerrero and Adán Pérez-García \\ Correspondence to: Andrea Guerrero (guerbach@gmail.com)
}

The copyright of individual parts of the supplement might differ from the article licence. 
S1. Estimated shell measures of juvenile specimens of Pleurosternon bullockii (Paracryptodira, Pleurosternidae), from the Berriasian (Early Cretaceous) of Swanage (Dorset, England). Abbreviation: N.A, not available. All the measures are in $\mathrm{cm}$.

\begin{tabular}{|c|c|c|c|c|}
\hline SPECIMEN & $\begin{array}{c}\text { Carapace } \\
\text { maximum } \\
\text { length }\end{array}$ & $\begin{array}{c}\text { Carapace } \\
\text { maximum } \\
\text { width }\end{array}$ & $\begin{array}{c}\text { Plastron } \\
\text { maximum } \\
\text { length }\end{array}$ & $\begin{array}{c}\text { Plastron } \\
\text { maximum } \\
\text { width }\end{array}$ \\
\hline NHMUK 48262 & 13.5 & 13 & N. A & N. A \\
\hline NHMUK 48263 & 11 & 10.5 & N. A & N. A \\
\hline NHMUK 48264 & 8.5 & 8 & N. A & N. A \\
\hline NHMUK 48263a & 5.5 & 5 & N. A & N. A \\
\hline NHMUK 48263e & 5.5 & 5 & N. A & N. A \\
\hline NHMUK 48347 & N. A & N. A & 13 & 12.5 \\
\hline NHMUK 48343 & N. A & N. A & 11.5 & 11 \\
\hline NHMUK 48344 & N. A & N. A & 5.5 & 4.5 \\
\hline
\end{tabular}

S2. Sample sizes of the analyses performed through the quantitative approach.

\begin{tabular}{|l|c|}
\hline \multicolumn{1}{|c|}{ Elements } & Sample size (N) \\
\hline Nuchal & 16 \\
\hline Third vertebral scute & 18 \\
\hline Anterior plastral lobe & 13 \\
\hline Entoplastron & 21 \\
\hline
\end{tabular}

S3. Definition of landmark location for the nuchal of Pleurosternon bullockii (Paracryptodira, Pleurosternidae), taking into account specimens from the Berriasian (Early Cretaceous) of Swanage (Dorset, England). 


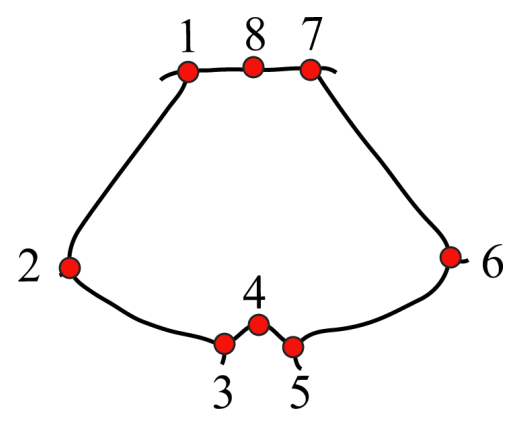

\begin{tabular}{|c|c|l|}
\hline View & Landmark & \multicolumn{1}{|c|}{ Anatomical definition } \\
\hline Dorsal & 1 & Anterior left contact between the nuchal and first peripheral \\
\hline Dorsal & 2 & Posterior left contact between the nuchal and first peripheral \\
\hline Dorsal & 3 & $\begin{array}{l}\text { Posterior left contact between the nuchal and the first element } \\
\text { of the neural row }\end{array}$ \\
\hline Dorsal & 4 & Medium point of posterior margin \\
\hline Dorsal & 5 & $\begin{array}{l}\text { Posterior right contact between the nuchal and the first } \\
\text { element of the neural row }\end{array}$ \\
\hline Dorsal & 6 & Posterior right contact between the nuchal and first peripheral \\
\hline Dorsal & 7 & Anterior right contact between the nuchal and first peripheral \\
\hline Dorsal & 8 & Medium point of anterior margin \\
\hline
\end{tabular}

S4. Definition of landmark location for the third vertebral scute of Pleurosternon bullockii (Paracryptodira, Pleurosternidae), taking into account specimens from the Berriasian (Early Cretaceous) of Swanage (Dorset, England).

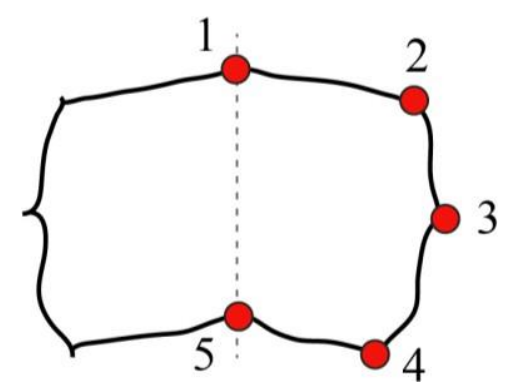

\begin{tabular}{|c|c|l|}
\hline View & Landmark & \multicolumn{1}{c|}{ Anatomical definition } \\
\hline Dorsal & 1 & Medium point of anterior margin \\
\hline
\end{tabular}




\begin{tabular}{|l|l|l|}
\hline Dorsal & 2 & Anterior contact between the anterior and lateral margin \\
\hline Dorsal & 3 & Contact between the antero- and postero-lateral margins \\
\hline Dorsal & 4 & Posterior contact between the lateral and posterior margins \\
\hline Dorsal & 5 & Medium point of posterior margin \\
\hline
\end{tabular}

S5. Definition of landmark and semilandmark location for the anterior plastral lobe of Pleurosternon bullockii (Paracryptodira, Pleurosternidae), taking into account specimens from the Berriasian (Early Cretaceous) of Swanage (Dorset, England).

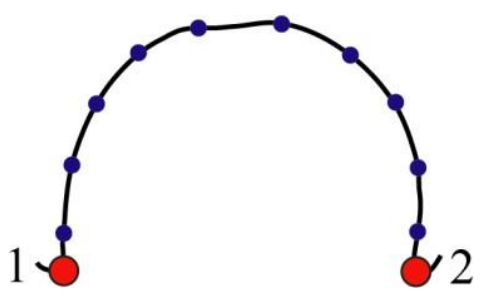

\begin{tabular}{|c|c|l|}
\hline View & Landmark & \multicolumn{1}{c|}{ Anatomical definition } \\
\hline Ventral & 1 & Right axially notch \\
\hline Ventral & 2 & Left axillary notch \\
\hline Ventral & $3-12$ & Semilandmarks: plate outline between LM1-LM2 \\
\hline
\end{tabular}

S6. Definition of landmark and semilandmark location for the entoplastron of Pleurosternon bullockii (Paracryptodira, Pleurosternidae), taking into account specimens from both the Tithonian (Late Jurassic) and Berriasian (Early Cretaceous) of England. 


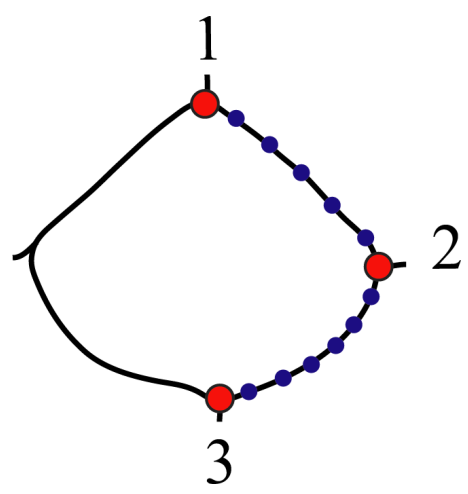

\begin{tabular}{|c|c|l|}
\hline View & Landmark & \multicolumn{1}{|c|}{ Anatomical definition } \\
\hline Ventral & 1 & Anterior-most point of entoplastron \\
\hline Ventral & 2 & Posterior contact between the entoplastron and epiplastron \\
\hline Ventral & 3 & Posterior-most point of entoplastron \\
\hline Ventral & $4-14$ & $\begin{array}{l}\text { Semilandmarks: plate outline between LM1-LM2 and LM2- } \\
\text { LM3 }\end{array}$ \\
\hline
\end{tabular}

S7. Principal Component Analysis considering the allometric components of shape for the shell of Pleurosternon bullockii (Paracryptodira, Pleurosternidae), taking into account specimens from the Berriasian (Early Cretaceous) of Swanage (Dorset, England). (a), Nuchal. (b), Third vertebral scute. (c), Anterior plastral lobe. (d), Entoplastron. Wireframes indicate the main shape changes of each PC, the light blue concerns the average shape, whereas the dark blue is the shape variance related to extreme of variation along the axis. Abbreviations: C, CAMSM; D, DORCM; N, NHMUK. 
(a)
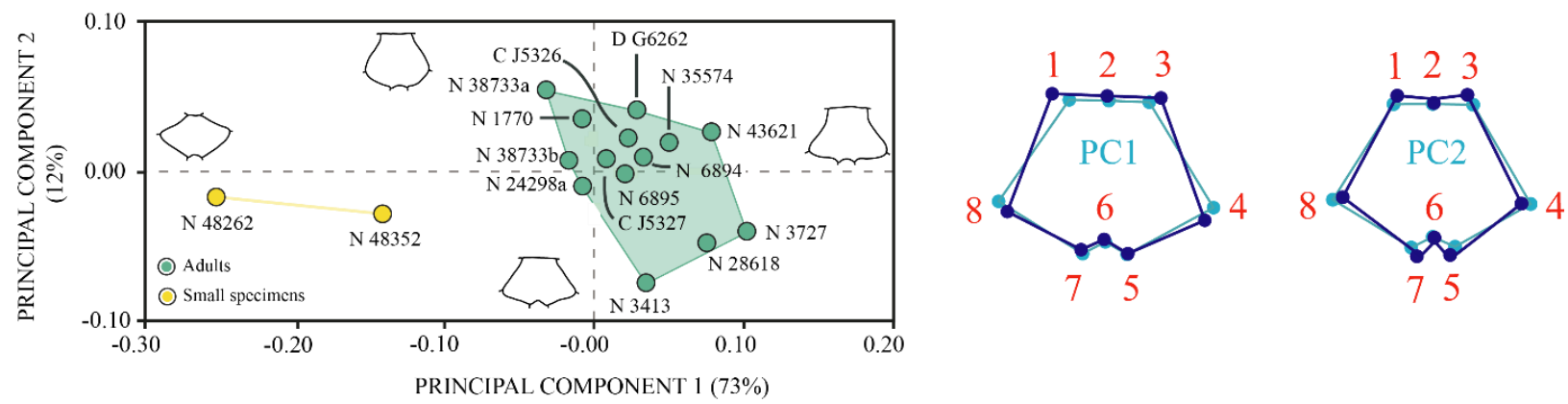

(b)
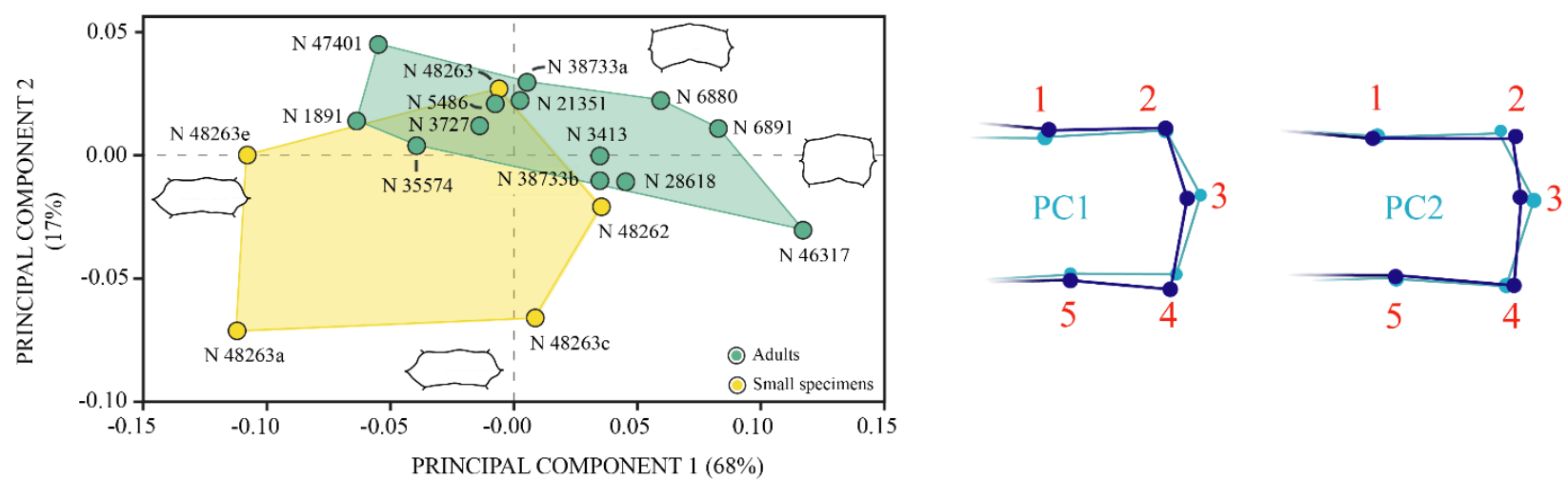

(c)
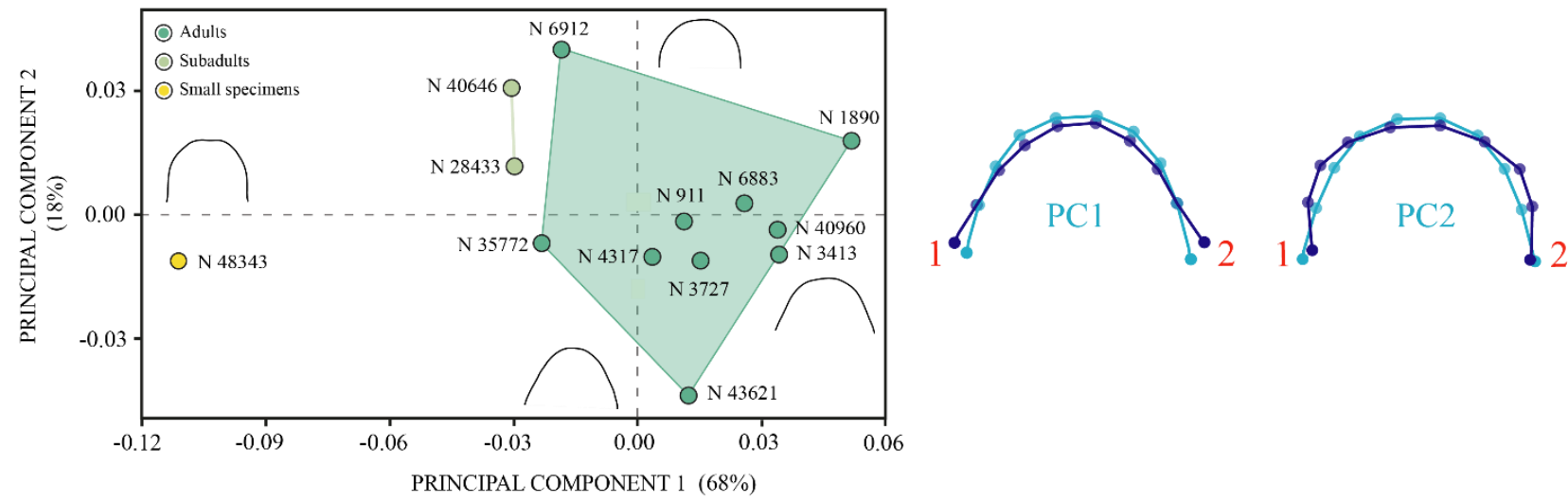

(d)
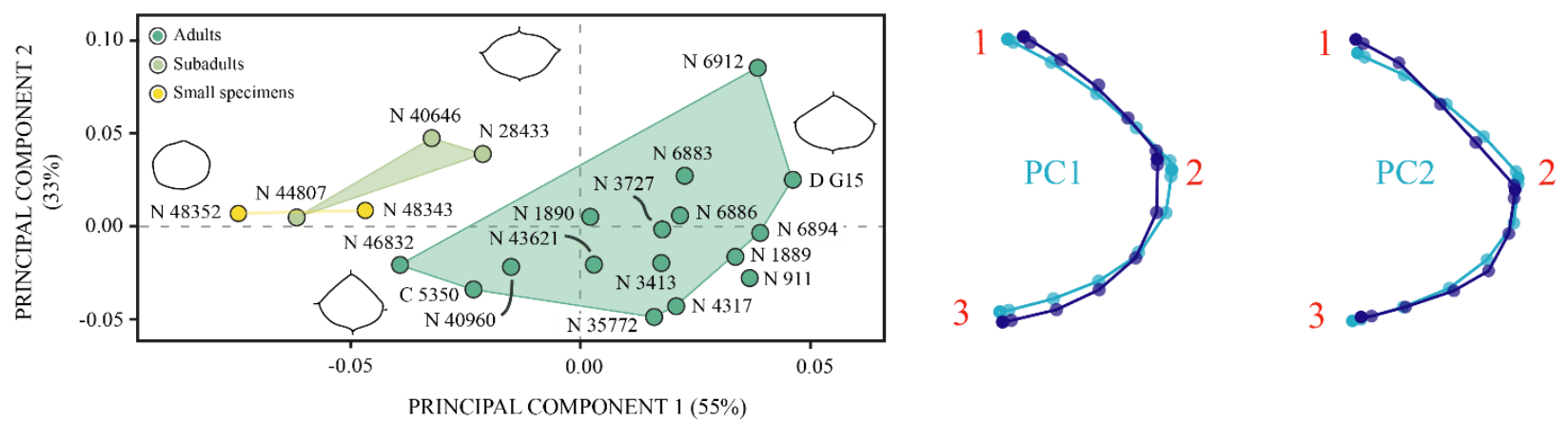
S8. P-P plots for diagnosing normal distribution of Procrustes residuals of the shell elements of Pleurosternon bullockii (Paracryptodira, Pleurosternidae), taking into account specimens from both the Tithonian (Late Jurassic) and Berriasian (Early Cretaceous) of England. (a), Nuchal. (b), Third vertebral scute. (c), Anterior plastral lobe. (d), Entoplastron.

(a)

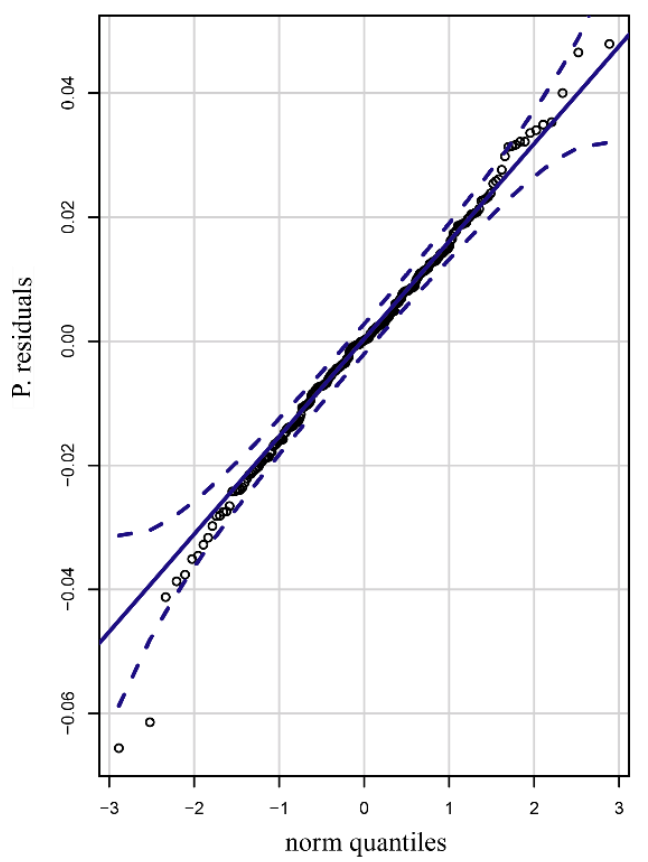

(c)

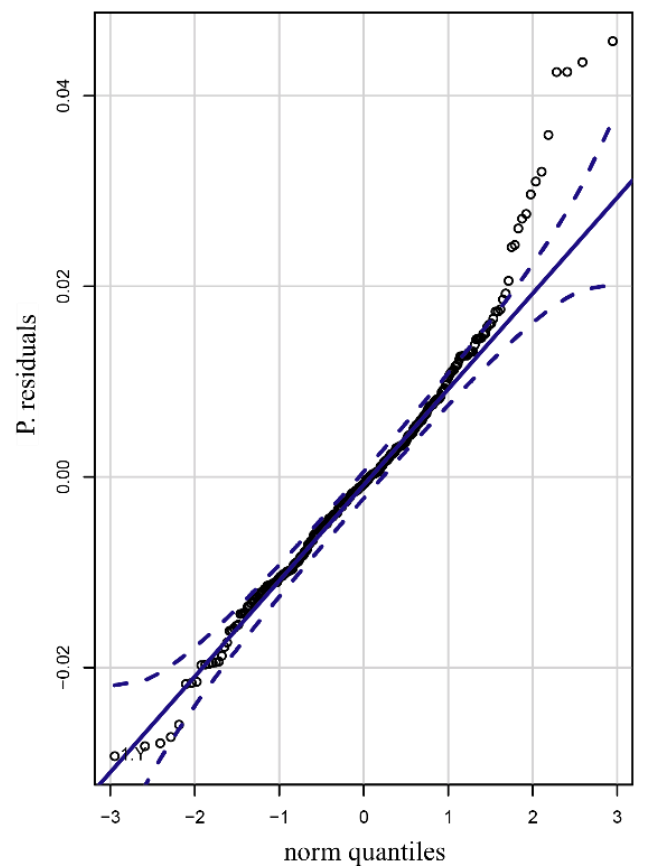

(b)

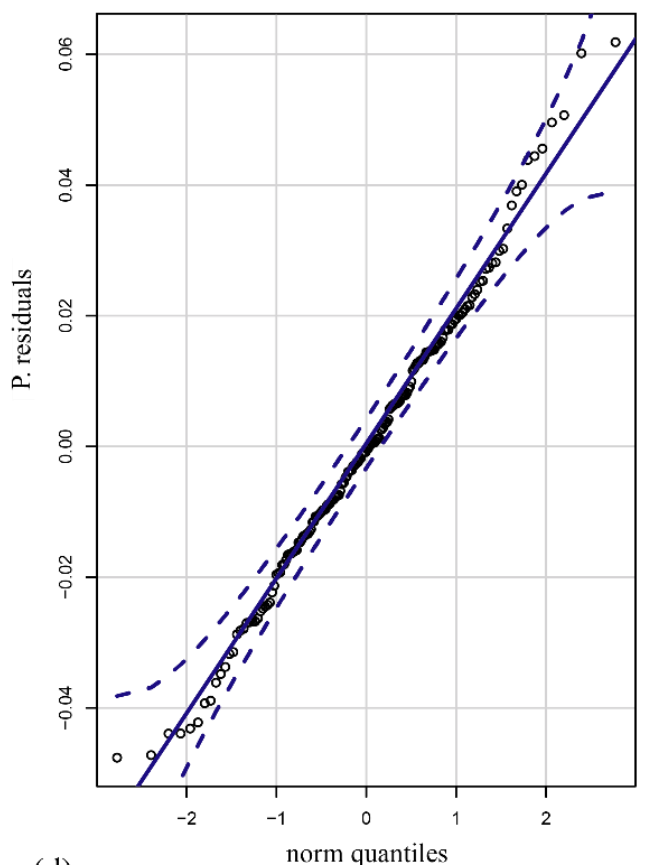

(d)

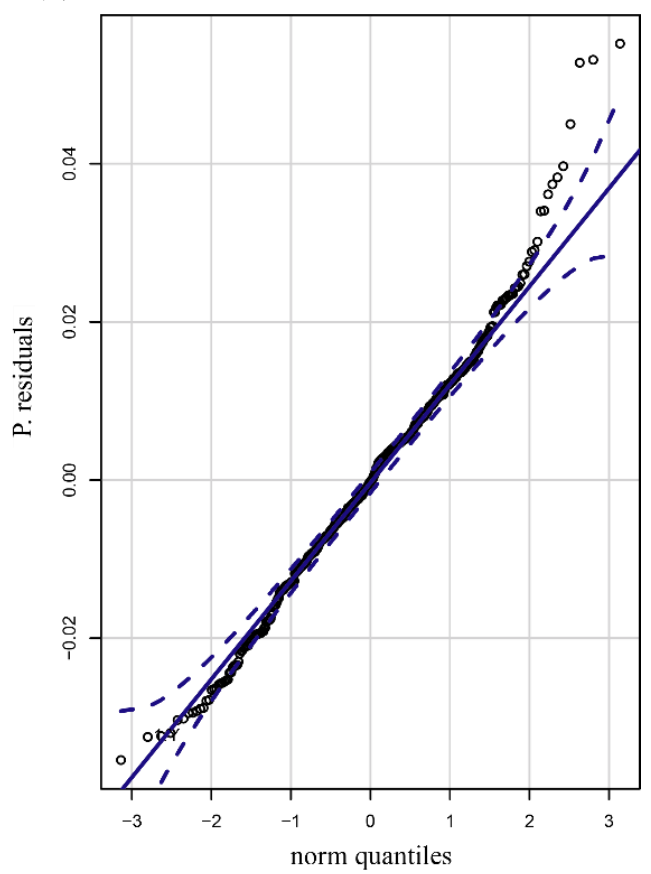


S9. Comparison of the carapace size recognized in different ontogenetic stages (adult and juvenile) of Pleurosternon bullockii (Paracryptodira, Pleurosternidae) from the Tithonian (Upper Jurassic) and Berriasian (Lower Cretaceous) of the United Kingdom. (a), Reconstruction of dorsal view of the juvenile carapace based on NHMUK 48262 and NHMUK 48263. (b), Reconstruction of dorsal view of the adult carapace based on CAMSM J5327. (c)-(d), Histogram of the carapace length (c) and width (d). Scale bar equals $2 \mathrm{~cm}$.

(a)

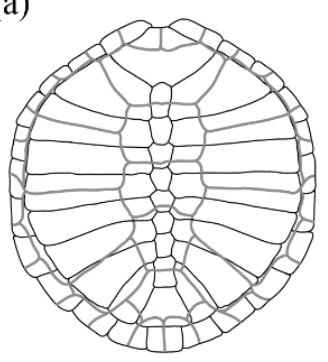

(c)

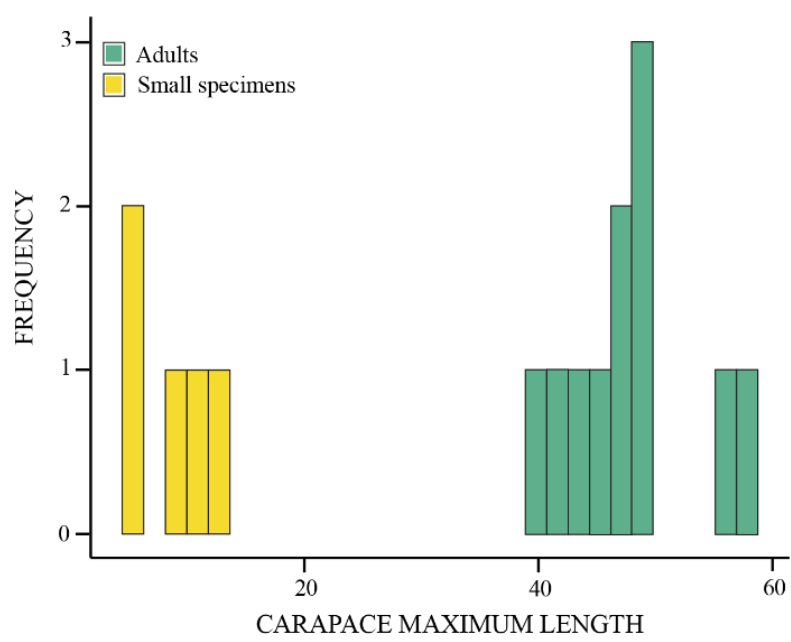

(b)

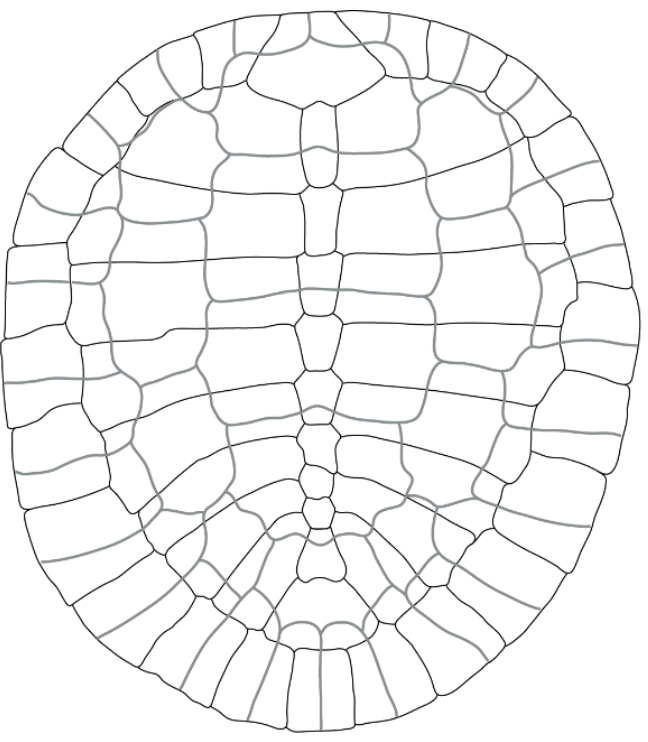

(d)

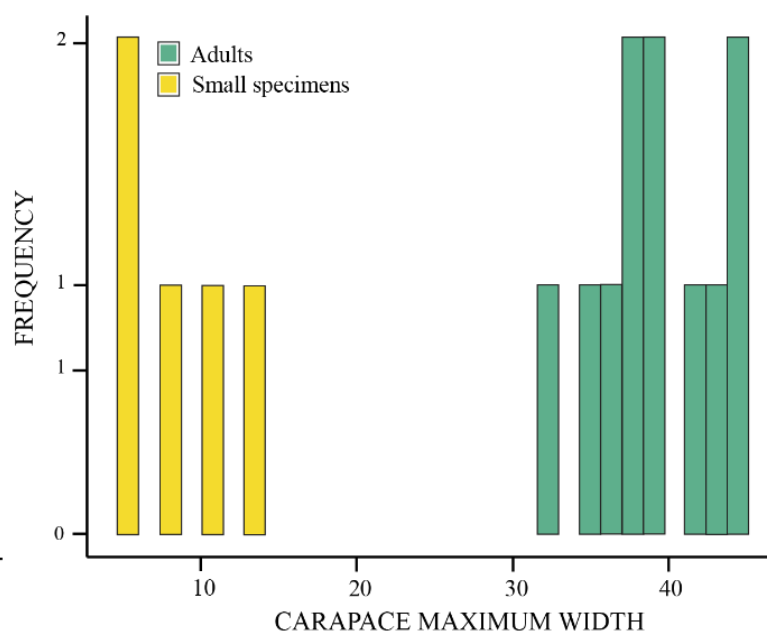


S10. Comparison of the plastron size recognized in different ontogenetic stages (adult, subadult and juvenile) of Pleurosternon bullockii (Paracryptodira, Pleurosternidae) from the Tithonian (Upper Jurassic) and Berriasian (Lower Cretaceous) of the United Kingdom. (a), Reconstruction of ventral view of the juvenile plastron based on NHMUK 48262, NHMUK 48343 and NHMUK 48347. (b), Reconstruction of ventral view of the subadult plastron based on NHMUK OR 28433. (c), Reconstruction of ventral view of the adult plastron based on NHM UK R 3413. (d)-(e), Histogram of the plastron length (d) and width (e). Scale bar equals $2 \mathrm{~cm}$.

(a)

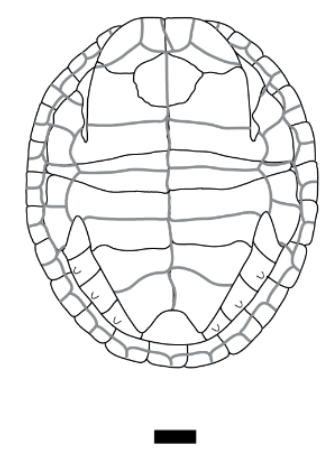

(d)

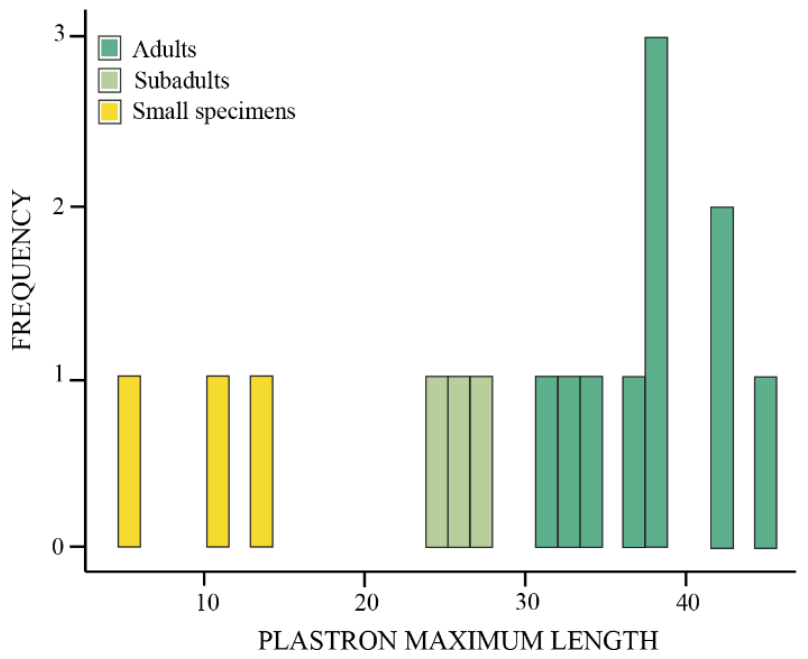

(b)

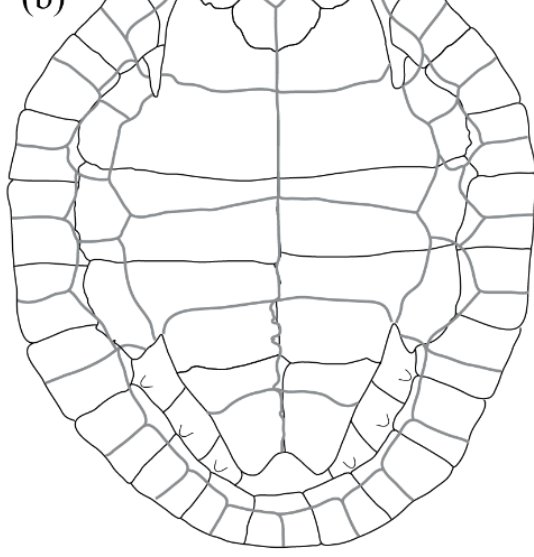

(c)

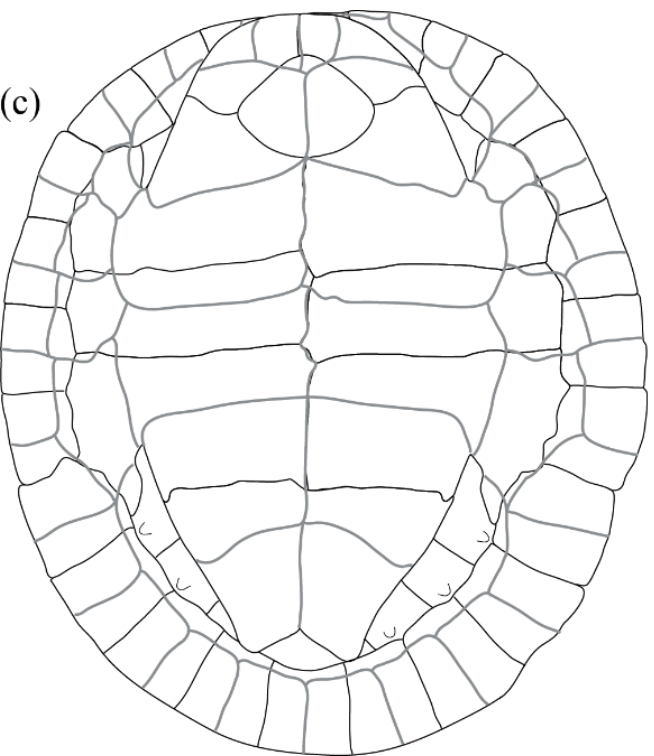

(e)

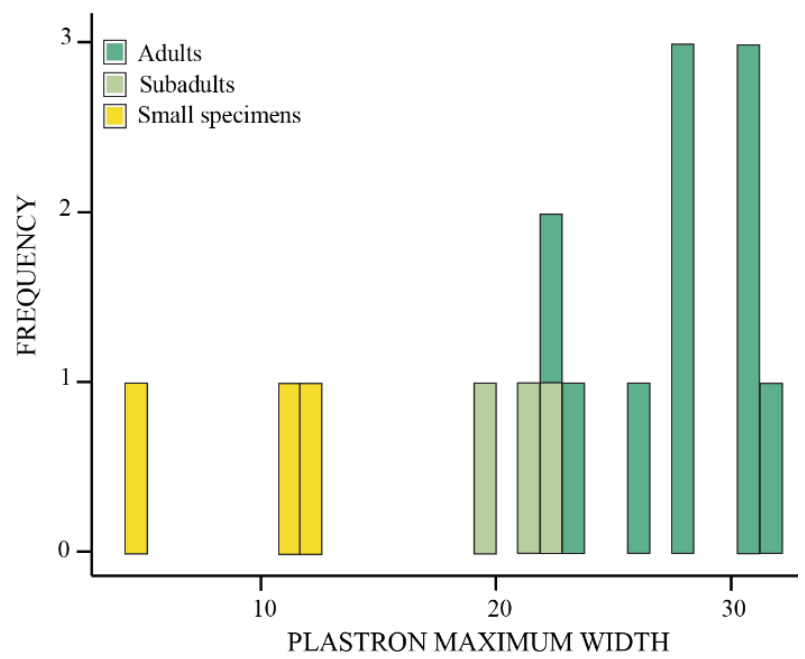

